\title{
EDUCAÇÃO NA PRIMEIRA REPÚBLICA: ALFABETIZAÇÃO E CULTURA ESCOLAR NA REVISTA DE ENSINO (1902-1910)
}

\author{
Louisa Campbell Mathieson \\ Universidade de São Paulo - Brasil.
}

Resumo

Este artigo tem por objetivo analisar o debate pedagógico referente à alfabetização veiculado na Revista de Ensino, publicada pela Associação Beneficente do Professorado Público de São Paulo. A periodização abrange os anos de 1902 a 1910. Procurou-se identificar elementos que possibilitassem a reconstituição da atmosfera mental da época, naquilo que se refere ao debate sobre alfabetização e métodos de ensino, isto é, sobre a cultura escolar. Assim, por meio da análise do discurso pedagógico, procurou-se examinar, também, os sentidos sociais dessa alfabetização, à luz das implicações da utilização da escola como instrumento político republicano para formação do povo.

Palavras-chave: imprensa periódica educacional, cultura escolar, alfabetização, civilidade.

\section{EDUCATION DURING THE FIRST REPUBLIC: LITERACY AND SCHOOL CULTURE IN THE JOURNAL OF EDUCATION (1902-1910)}

\section{Abstract}

This article aims to analyze the pedagogical debate on literacy that was ran by the Journal of Education, published by the São Paulo Public School Teachers Beneficent Association. The timeline covers the years from 1902 to 1910 . We sought to identify elements that allow the reconstruction of the intellectual atmosphere of the time - in the debate about literacy and teaching methods, in other words, about the school culture. Thus, through the analysis of pedagogic discourse, we tried to also examine the social meanings of literacy in light of the implications of using the school as a Republican political tool for the forming of the people.

Key-words: educational periodical press, school culture, literacy, civility.

\section{EDUCACIÓN EN LA PRIMERA REPÚBLICA: ALFABETIZACIÓN Y CULTURA ESCOLAR EN LA REVISTA DE ENSEÑANZA (1902-1910)}

Resumen

En este artículo se pretende analizar el debate pedagógico sobre el tema de la alfabetización en la Revista de Enseñanza, publicado por la Associación Benéfica de los Maestros de Escuelas 
Públicas de São Paulo. El cronograma abarca los años de 1902 a 1910. Hemos tratado de identificar los elementos que permiten la reconstrucción de la atmósfera mental de la época - en el debate sobre los métodos de alfabetización y la enseñanza, es decir, sobre la cultura escolar. Así, a través del análisis del discurso pedagógico, hemos tratado de examinar también el significado social de la alfabetización a la luz de las consecuencias de utilizar la escuela como una herramienta política republicana para la formación de la población.

Palabras-clave: prensa periódica educacional, cultura escolar, alfabetización, civismo.

\section{L'ÉDUCATION ABORD DANS LA PREMIER RÉPUBLIQUE: ALPHABÉTISATION ET CULTURE SCOLAIRE DANS LE MAGAZINE DE L'ENSEIGNEMENT (1902-1910)}

Résume

Cet article vise à analyser le débat pédagogique sur le thème de l'alphabétisation à exécuter le Magazine de l'Enseignement, publié par Association Bénévole des Enseignants des Écoles Publiques de São Paulo. Le calendrier couvre les années 1902-1910. Nous avons cherché à identifier les éléments qui permettent la reconstruction de l'atmosphère mentale de l'époque - ce qui revient au débat sur les méthodes d'alphabétisation et d'enseignement, à savoir, la culture scolaire. Ainsi, à travers l'analyse du discours pédagogique, nous avons essayé d'examiner également la signification sociale de l'alphabétisation à la lumière des implications de l'utilisation de l'école comme un outil politique républicain pour la formation des personnes.

Mots-clé: éducation de la presse périodique, culture scolaire, alphabétisation, civilité. 
Aos nove anos, eu era quase analfabeto. E achava-me inferior aos Mata Lima, nossos vizinhos, muito inferior, construído de maneira diversa. Esses garotos, felizes, para mim eram perfeitos: andavam limpos, riam alto, freqüentavam escola decente e possuíam máquinas que rodavam na calçada como trens. Eu vestia roupas ordinárias, usava tamancos, enlameava-me no quintal, engenhando bonecos de barro, falava pouco.

Graciliano Ramos, Infância, 1993, p. 187.

\section{Introdução}

$1 \mathrm{~s}$ instituições educacionais ocuparam grande parte do debate político do século 20, tendo a alfabetização servido de termômetro social, pois que, com a Modernidade e com o consequente processo de escolarização da sociedade, a alfabetização passou a ser vista como virtude e como requisito para se exercer um julgamento bom, ou ao menos razoável, sobre a realidade. $\mathrm{O}$ analfabetismo, em contrapartida, passou a ser associado não só ao fracasso escolar, mas também ao fracasso individual frente a uma sociedade letrada, marcada pela leitura e escrita. Como Jack Goody (2006) escreve, a cultura letrada promoveu a estratificação social, funcionando a leitura e a escrita como ferramentas de diferenciação entre as pessoas, porquanto aqueles que lêem passam a ter hábitos e refinamentos tais que os distinguem daqueles que não lêem.

Compreender a educação no começo do século 20 no Brasil significa, em alguma medida, entender o processo de alfabetização da população. Assim, é por meio do ensino dos rudimentos da leitura, da escrita e dos cálculos que se configuram as orientações morais do projeto republicano de civilizar o povo. A escola, aos olhos da época, visava a erradicar a ignorância que grassava por todo o país. Buscava-se preparar a nação brasileira para a sedimentação da recente República.

Nesse cenário, a imprensa periódica educacional surgiu como importante suporte material de orientação didática e de formação do magistério, pois ela tinha dupla intenção: formar os professores e informá-los de fatos e de acontecimentos. Criou-se, assim, por meio do discurso promovido pela imprensa periódica, um espaço comum aos professores para a discussão de questões educacionais. Desse modo, a impressa periódica educacional, por um lado, trazia aos professores dados novos sobre pedagogia e, por outro, agia como motivadora do debate político e educacional. Portanto, é um espaço que possibilita ao pesquisador da área de História da Educação a percepção de tendências do pensamento coletivo e da atmosfera mental de uma época.

A imprensa periódica pedagógica, como retrata António Nóvoa em um importante estudo sobre o tema, é "o melhor meio para aprender a multiplicidade do campo educativo" (1993, p. 32). Pierre Caspard e Pénélope Caspard (2002) a conceituam como documento que tem como característica ser testemunho vivo de métodos e de concepções pedagógicas.

Pela leitura dos periódicos pedagógicos, pode-se notar que os artigos são atravessados por aspectos políticos e morais, o que permite ao pesquisador ter contato com parte da dimensão social da época estudada: 
Estudo específico e interno ao próprio periódico e sua produção, a partir do qual é possível reconstruir, num momento dado, estágios de funcionamento e estruturação do campo educacional, movimentos de grupos de professores, disputas e atuações. Dito de outro modo, é possível partir do estudo de determinados periódicos educacionais e tomálos como núcleos informativos, enquanto suas características explicitam modos de construir e divulgar o discurso legítimo sobre as questões de ensino e conjunto de prescrições ou recomendações sobre formas ideais de realizar o trabalho docente. (Catani; Sousa, 1999, p. 11)

Assim, a escolha da Revista de Ensino (1902-1918) ${ }^{1}$ aconteceu pelo entendimento de que esse periódico representa um importante material de suporte que contempla discursos educacionais de diferentes educadores da época, bem como permite aproximação e confronto com os acontecimentos e os debates ocorridos durante o período de publicação. Dessa maneira, os periódicos pedagógicos, entendidos como uma fração significativa do debate educacional, proporcionam a reconstrução de uma parte da vivência pedagógica da época.

A Revista de Ensino, em seu ciclo de vida, trouxe discussões a que o grupo de professores não poderia estar alheio, tais como o fornecimento de material para o trabalho pedagógico, a orientação em relação à prática, a publicação de críticas e de notícias sobre as obras didáticas, a transmissão das principais tendências do ensino e a divulgação de mudanças legais no ensino. Como retrata Antonio d'Ávila,

o ensino público paulista teve na década de 1900-1909 um dos períodos mais brilhantes de sua história. A fundação da Associação Beneficente do Professorado Paulista, a publicação da Revista de Ensino, a floração de espíritos dos mais talentosos de uma geração de mestres ilustres deram a essa fase de nossa evolução pedagógica o seu aspecto talvez mais fecundo. (1946, p. 101-102)

Denice Catani (1989) escreve que a relevância da investigação histórico-educacional em periódicos pedagógicos centra-se na possibilidade de analisar, por intermédio de fontes primárias, os valores culturais, políticos e sociais presentes em uma época. Reaver aspectos da vivência educacional de São Paulo no começo do século passado pode ser um instrumento privilegiado para se pensar as práticas escolares e a cultura escolar de uma época, visto que os periódicos atuaram no sentido de projetar mudanças no campo educativo.

A partir do estudo das práticas escolares e acerca dos métodos e das técnicas referentes ao ensino da primeira leitura, é que se estruturou o estudo da cultura escolar vinculado às questões sociais, tendo em vista que a alfabetização se apresenta como uma prática estruturante e formadora do nosso tempo. Nesse sentido, o conceito de cultura escolar é aqui entendido como um conjunto de normas que define os conhecimentos a ensinar e as condutas a incentivar, além de ser também um conjunto de práticas que permite transmitir esses conhecimentos e incutir nos sujeitos os comportamentos desejados (Julia, 2001).

\footnotetext{
${ }^{1}$ A Revista de Ensino foi publicada em São Paulo pela Associação Beneficente do Professorado Público do Estado de São Paulo nas duas primeiras décadas do século 20. Os artigos podem ser localizados nos diferentes volumes da Revista de Ensino, esta encontrada no acervo de obras raras - Biblioteca Paulo Bourroul - da Biblioteca da Faculdade de Educação da Universidade de São Paulo.
} 
O presente artigo buscou analisar os artigos da Revista de Ensino na mesma linha em que Dominique Julia (2001) defende o conceito de cultura escolar. Assim, o conceito de cultura escolar é empregado como uma categoria de análise apta a indicar o modo pelo qual a imprensa periódica educacional lidava com o debate acerca do ensino da leitura e da escrita. Por um lado, a Revista de Ensino prescreveu, em seus artigos, como devia ser a alfabetização e, por outro, descreveu as práticas que ocorriam no interior das escolas, tais como: questões de espaço e tempo, currículos, métodos de ensino. A Revista de Ensino teve uma forte influência na difusão de modelos, de métodos e de ideias pedagógicas, ou seja, de cultura escolar. O enfoque desta pesquisa se vale dessa influência.

O propósito principal deste artigo é analisar a temática da educação na Primeira República, por meio dos discursos veiculados em um periódico pedagógico paulista, a Revista de Ensino (1902-1918), dirigido aos professores e que aborda a concepção de leitura, de métodos e de estratégias de alfabetização, a partir das perspectivas dos autores e colaboradores no âmbito do periódico. Com a apreensão da influência que a Revista exerceu na difusão de modelos e de ideias pedagógicas é que o conceito de cultura escolar se fez presente como categoria de análise empírica. Assim, o objetivo específico do presente artigo é identificar elementos que possibilitem, de algum modo, a reconstituição da atmosfera mental da época, naquilo que se refere ao debate sobre educação, métodos e estratégias para o ensino da primeira leitura. Nesse sentido, procurou-se examinar, também, os sentidos sociais da alfabetização então discutida e proposta à luz das implicações sócio-culturais da utilização da escola como instrumento político republicano que integrava um projeto mais amplo de formação da cidadania do povo.

Para alcançar seu objetivo, o presente artigo centrou-se, primeiramente, na reconstituição de parte do debate acerca dos métodos e das técnicas de alfabetização difundidos pela Revista de Ensino entre os anos de 1902 e 1910. Especial atenção foi dada, todavia, aos três anos iniciais de publicação, 1902-1904, pois foi nesse período que se encontrou a maior parte de artigos sobre a temática do ensino da leitura. Depois a atenção se concentrou no período situado entre os anos de 1905 a 1910: nessa fase, devido à falta de recursos financeiros para a publicação da revista, percebeu-se alteração de enfoque no discurso do periódico, o que provocou mudanças no tom dos artigos. A terceira e última fase da Revista de Ensino, com início em 1910 e término em 1918, não é abordada neste artigo, pois é o momento em que o governo toma para si a iniciativa de publicação do periódico e o enfoque dos debates muda completamente ao assumir o discurso do governo.

Essa divisão dos momentos da Revista de Ensino está baseada na tese de Denice Catani (1989). Em geral, mudanças no debate podem ser compreendidas por meio do que Maria Helena Bastos (2002) caracteriza como influência significativa no discurso veiculado em periódicos, ou seja, ocorrem quando um assunto é trabalhado no sentido de perpetuar ou de cristalizar determinados discursos em detrimento de outros, conforme a ressonância e a importância dada para cada tema publicado.

A reconstituição de parte da vivência educacional do Brasil parece ser um instrumento privilegiado para se pensar a validação histórica das práticas escolares de hoje. De acordo com José Mário Pires Azanha (1992), pressupõe-se que há a 
possibilidade de se alcançar a totalidade de um cotidiano, isto é, a atmosfera mental de uma época a partir da apreensão de uma parte dele. Assim, para se analisar a temática da educação brasileira na Primeira República foi escolhido o debate interno aos periódicos pedagógicos, por esses revelarem temas de profundidade acerca da educação no Brasil no período em questão:

Embora cultura escolar não seja um conceito simples de delimitar, considera-se que na escola foram sendo historicamente construídas normas e práticas definidoras dos conhecimentos que seriam ensinados e dos valores e comportamentos que seriam inculcados, gerando o que se pode chamar de cultura escolar. Conhecimentos, valores e comportamentos que, embora tenham assumido uma expressão peculiar na escola, e, principalmente, em cada disciplina escolar, são produtos e processos relacionados com as lutas e os embates da sociedade que os produziu e foi também produzida nessa e por essa escola. (Pessanha; Daniel; Menegazzo, 2004, p. 58)

Desse modo, Caspard (2002) diz que a imprensa periódica pedagógica validou-se como local de popularização das ideias, de ordem teórica e de ordem prática da educação, pois é um suporte material dinâmico para revelar as questões educacionais, interagindo com os movimentos sociais e as questões políticas de um período histórico. Com a instauração da República, a imprensa periódica pedagógica desempenhou importante função na disseminação de materiais, no sentido de transcrever, prescrever e debater métodos e concepções pedagógicas, sendo um meio de fácil acesso devido ao baixo custo (Bastos, 2002).

Concomitantemente a esse processo de disseminação de materiais e de prescrição de práticas, a imprensa periódica pedagógica foi aliada dos professores, tanto no processo de sistematização dos programas de ensino, quanto como ferramenta de auxílio aos professores, tendo em vista a insuficiência dos cursos de formação de professores, associada, ainda, a dois outros fatores: a dificuldade de frequentar cursos de formação e os altos custos dos livros.

O presente trabalho pressupõe como corpus de análise a Revista de Ensino, publicada na capital paulista pela Associação Beneficente do Professorado Público do Estado de São Paulo, nas duas primeiras décadas do século 20. A partir desse material, utilizou-se, como estratégia de pesquisa, a classificação da fonte documental, ou seja, a sistematização dos artigos sobre alfabetização. Por meio da leitura e da apreensão do discurso pedagógico veiculado pela Revista de Ensino sobre os temas ligados ao papel da alfabetização como elemento central da escola primária, elegeram-se algumas categorias operatórias de análise, pelas quais se construiu a pesquisa. Tal metodologia foi utilizada a fim de ordenar o processo de entendimento do conteúdo do material de pesquisa. As categorias trabalhadas na análise interna à revista foram: ensino, alfabetização, leitura e escrita.

Procurou-se estudar como as categorias analíticas aparecem nos artigos que abrangiam o assunto do ensino da leitura e da escrita na escola primária. Simultaneamente ao processo de classificação da fonte documental, foi feita uma pesquisa bibliográfica a respeito da temática escolhida para amparo teórico e metodológico do trabalho. Para tanto, analisou-se o conteúdo retirado da Revista de 
Ensino, tanto do ponto de vista da História da Educação, quanto sob a óptica dos estudos de alfabetização, pois a análise empírica apenas se faz sentir a luz de conceitos teóricos.

\section{Estrutura interna da Revista de Ensino}

A Revista de Ensino foi publicada em São Paulo nas duas primeiras décadas do século 20, com algumas interrupções. O lançamento da revista ocorreu em um momento de expressivo crescimento da capital paulista, quando os imigrantes ${ }^{2}$ já representavam um número considerável da população e, desse modo, a questão da consolidação da língua era de caráter prioritário para a construção da identidade nacional. À vista disso, ficava a cargo da escola disseminar a língua portuguesa. Assim, o período estudado é marcado por intensa atividade do setor educacional, a qual é caracterizada pelo baixo investimento na formação dos professores, pela preocupação com a adoção e o investimento em métodos de ensino e pela falta de prédios escolares.

Refletir acerca de um periódico exige uma análise empírica de sua estrutura interna. Os autores da Revista de Ensino caracterizam-se por serem alunos egressos da Escola Normal da capital paulista ou profissionais que ocupavam cargos privilegiados do sistema educacional. Os destinatários da revista, ou seja, os leitores, eram, em geral, professores e profissionais da área de educação. Já o texto apresenta uma preocupação com os rumos do país e a crença positivista de que seria por meio da escola que se reorganizaria socialmente a nova nação. Assim, percebe-se pela interação desses três elementos autor, leitor e texto - que há uma aposta na educação moral, no civismo e na nacionalidade, características que são fortemente debatidas ao longo da revista.

A Revista de Ensino começou a ser publicada em 1902 por "iniciativa de um grupo de professores e profissionais ligados à educação que havia há pouco se congregado para a criação de uma entidade chamada Associação Beneficente do Professorado Público de São Paulo" (Catani, 1989, p. 42). Esta associação foi criada em 27 de janeiro de 1901, como entidade que tencionava agremiar os professores do Estado de São Paulo. No entanto, por denúncias e críticas ao governo, houve uma ruptura entre este e a Associação no ano de 1905. A ruptura fez com que a revista passasse a ser impressa em uma tipografia privada. Tal mudança provocou alteração no tom do debate interno ao periódico, além de irregularidade nas publicações.

Catani (1989) divide o ciclo da Revista de Ensino em três momentos, a saber: 1ํ) 1902-1904: o período é marcado pelo tom moderado dos artigos. Os articulistas reconhecem-se como especialistas da área de educação e acreditam que podem orientar as ações de outros professores, bem como propiciar debates sobre as medidas oficiais. Porém, 1904 é um ano decisivo para o ciclo da Revista, pois, diante de uma medida governamental - um corte de $15 \%$ nos salários dos professores -, a Revista, enquanto meio de defesa do professorado e, acima disso, da educação, viu-se no dever de publicar

\footnotetext{
${ }^{2}$ Um dos elementos importantes e impulsionadores de alteração do setor social na Primeira República, como Jorge Nagle (1976) escreve, é o processo imigratório, tendo o seu período áureo entre 1888-1914. A imigração foi um elemento importante na alteração do mercado de trabalho e das relações trabalhistas. Com a ida dos escravizados para o sul, por volta de 1870, São Paulo, desde 1876, começou a organizar o serviço de imigrantes para suprir a mão-de-obra nas fazendas de café, sendo que a abolição da escravatura, em 1888, significou o deslocamento definitivo da economia para a região sudeste e sul do país com o consequente declínio dos proprietários de açúcar, mormente do nordeste. Outro aspecto que precisa ser levado em conta é a utilização da imigração como meio de branqueamento da população.
}
Hist. Educ. [Online]
Porto Alegre

v. 17

n. 41

Set./dez. 2013

p. 177-194 
críticas às ações oficiais, as quais, segundo os articulistas, propiciavam a deterioração do ensino público. 2º ) 1905-1910: o momento é marcado pelo distanciamento entre a Associação e o governo, tendo como consequência a radicalização do discurso por parte do professorado. Outro fato importante é a dificuldade financeira da Associação que, sem a contribuição do governo, não consegue manter a regularidade da publicação da Revista de Ensino. 3ํ) 1911-1918: é o momento em que a diretoria da Instrução Pública toma para si a iniciativa de edição da Revista de Ensino.

No bojo dessas relações políticas, econômicas e sociais, São Paulo firmou-se como Estado modelo para o restante do país ${ }^{3}$. A primeira publicação da revista ocorreu em 1902, momento de exacerbado crescimento de São Paulo. Assim, os acontecimentos políticos, econômicos e sociais da cidade de São Paulo são estampados nas páginas do periódico que passa a ser, muitas vezes, um local de respostas aos dilemas e às dificuldades do momento histórico que circunda a cidade, tal como problematiza llíada Silva (2004, p. 257):

Os discursos dos organizadores da Revista de Ensino podem ser lidos no cruzamento de duas tensões, de um lado, a produção de um discurso de caráter ofensivo, cuja intenção é eliminar as sobrevivências da tradição monárquica e, de outro, um discurso de caráter defensivo, perante a intensificação das questões sociais, que ambiciona desenvolver uma política integradora capaz de diluir os conflitos sociais. Ambos resíduos do antigo e emergência do novo insistiam em perpetuar o projeto de enraizamento de sentimentos consensuais. É nessa dimensão que se inscreve o discurso da Revista de Ensino. Fica difícil pensar o projeto pedagógico da Revista sem estabelecer as relações com estas problemáticas.

A história da educação brasileira, como constata Catani (1989), costumava retratar metaforicamente as duas primeiras décadas do século 20 como um tempo à meia-luz, visto que se costumava diminuir a importância dessa época, dando relevância às décadas posteriores. Todavia, o primeiro quartel do século 20 demonstra grande anseio por uma reforma da educação pública, pois se acreditava que, caso essa educação atendesse às massas, os preceitos republicanos de civilização do povo iriam tomar forma. Assim, a reforma da educação era tida como o único caminho possível para emplacar as mudanças sociais em direção ao progresso, no sentido de construir um futuro mais positivo mediante o aperfeiçoamento da sociedade.

O objetivo da educação, no início do século 20 no Brasil, é transformar a sociedade por meio da instrução das massas, com o intuito de embutir-lhes a noção de patriotismo. Assim, o discurso da escola republicana é permeado pelo discurso político acerca da alfabetização, ou como Maria Mortatti (2000b, p. 21) escreve, "tanto naquela como em nossa época, a alfabetização é apresentada como um dos instrumentos privilegiados de aquisição do saber e, portanto, de esclarecimento de massas". Acreditava-se que, por meio da difusão das primeiras letras, seriam curados os males que afetavam a sociedade, pois se esperava que o ser humano escolarizado obtivesse o manejo cívico do alfabeto.

Marta Carvalho (1989) aponta, entretanto, que o projeto republicano de

\footnotetext{
${ }^{3}$ Colimava-se a estruturação de um sistema modelar de ensino para o resto do país, principalmente após a reforma Caetano de Campos em 1891. Hist. Educ. [Online] Porto Alegre

v. 17

n. 41 Set./dez. 2013 p. $177-194$
} 
escolarização tinha, para a educação, um papel superestimado, pois os republicanos compreendiam o país como uma estrutura social amorfa e o lugar da educação seria regenerador. Buscava-se "transformar os habitantes em povo" (lbid., p. 9). Portanto, à época, a escolarização era entendida como uma obra de modelagem que tinha uma missão a cumprir.

Feito esse breve recorte histórico de reconstituição do ciclo da Revista de Ensino, passa-se ao objetivo de pesquisa mais específico: a análise interna da revista. Por meio da apreensão discursiva dos artigos do periódico, buscou-se obter informações relevantes, tanto sobre as concepções pedagógicas, quanto sobre as práticas de alfabetização nas primeiras décadas do século 20. Para tanto, foram analisados, prioritariamente, os artigos acerca dos métodos de alfabetização, porém, a partir desses buscou-se também sinais e indícios (Ginzburg, 1990) que possibilitassem compreender as decorrências do ensino da leitura e da escrita no processo de construção da nação, pois a alfabetização era utilizada como ferramenta política na constituição da cidadania e da civilidade da República recém-instaurada.

\section{Revista de Ensino: primeiro momento (1902-1904)}

A partir de abril de 1902, a Associação Beneficente do Professorado Público do Estado de São Paulo passou a publicar a Revista de Ensino. O primeiro momento, compreendido entre 1902 e 1904, caracteriza-se por ser um período marcado pelo tom suavizado dos artigos da revista. Os articulistas reconhecem-se como especialistas da educação e acreditam poder orientar as ações de outros professores. Assim, lê-se no editorial da primeira edição que o objetivo da Associação era,

por todos os meios de seu alcance, não só facilitar a tarefa do mestre, divulgando os melhores métodos e processos de ensino, como se empenhará, com o maior desvelo, para orientar o governo e os nossos legisladores na elaboração das leis futuras sobre instrução pública. [...] O professor primário, como elemento modificador, é o mais importante na evolução social. (1902, p. 3)

Como Silva (2004) escreve em sua tese, a Revista de Ensino tinha o objetivo de abarcar os interesses dos professores, facilitar a divulgação pedagógica e orientar os governantes na feitura das leis. Observa-se que, nos anos iniciais de publicação do periódico, havia um grande impasse sobre quais seriam os ideais que iriam compor o projeto de uma nova escola destinada para o povo. Os princípios educacionais apresentados pela revista são: ciência, educação moral e cívica e preparação para o trabalho. Nesse sentido, com a educação moral das crianças esperava-se que a escola se tornasse uma instituição vocacionada a produzir um sujeito ativo, trabalhador e responsável.

Em clima de debates em torno dos métodos, a Revista de Ensino apresentou-se como espaço adequado para a discussão dessa temática. Nesse sentido, um importante artigo que pode ser encontrado sobre o referido tema é de autoria de Roman Roca Dordal, Cartilha moderna. Nos primeiros parágrafos, Roca Dordal (1902) aborda a importância de o grupo de professores se questionar a respeito dos livros didáticos a serem usados em sala: "não há professor que possa ser indiferente quando se trata da cartilha, do primeiro livro que há de dar ao seu novo aluno" (Ibid., p. 213). Logo após esse 
questionamento, Roca Dordal entra na implicação direta que a escolha de uma cartilha traz, isto é, qual método será usado. Para tanto, o autor inicia a discussão relembrando a palestra ministrada pelo professor João Köpke, em 1886, quando este expôs o método analítico como seu método de ensino. Roca Dordal afirma que o método de Köpke é o mais racional, porquanto impõe a lógica, desenvolve a aprendizagem de forma ordenada: do mais simples para o mais complexo. O método de Köpke, como Roca Dordal explica, inicia-se com o professor fazendo um desenho no quadro negro. Depois, faz-se a escrita desse desenho, composta por uma palavra, até se chegar finalmente à frase. Roca Dordal pondera, entretanto, que não seria possível a utilização desse método nas escolas públicas, porque o ensino público não mais poderia ser individualizado ${ }^{4}$. Além disso, Roca Dordal entende a cartilha como uma auxiliar necessária da prática de ensino.

Quando debate sobre o método de Köpke, Roca Dordal ressalta a importância do desenho para o ensino da leitura, pois é uma das maneiras de se representar o mundo. Todavia, Roca Dordal aponta o desenho como um aspecto negativo do método de Köpke pelo fato de que, provavelmente, muitos professores não saibam desenhar. Roca Dordal argumenta, ainda, que a Cartilha moderna é a que mais contém desenhos e, seguido desses, estão exercícios para se trabalharem as vogais mediante o uso de pequenas palavras. O autor propugna que o método é a configuração de cada passo. Assim, as cartilhas, para Roca Dordal, devem ser estruturadas no sentido de que cada página seja uma preparação para a seguinte. Ler, para ele, "é dizer uma sentença que exprima uma idéia completa" (Roca Dordal, 1902, p. 217). Esse autor anota, ainda, que a escolha do método é atribuída à ideia de eficiência, pois, para ele, a questão de tempo é de suma importância: "o ensino da leitura deve ser obtido do mais simples para o mais completo e, no menor prazo possível” (lbid., p. 217).

Joaquim Luiz Brito escreveu uma resenha também intitulada Cartilha moderna, pela qual dialogou com o artigo de Roca Dordal. Nela, o autor comenta que os professores brasileiros, historicamente, foram inimigos dos métodos de palavração americanos crítica centrada na figura da professora Miss Márcia Browne, da Escola Americana -, sendo que também foram, em certa medida, contrários ao método de João Köpke, "por não ser ele aplicável em nossas escolas, onde o ensino é feito coletivo e não individualmente, e nem serem todos os professores desenhistas" (Brito, 1902, p. 321). Contudo, a Cartilha moderna, o suporte didático de Roca Dordal, é baseada na palavração. Apesar disso, para Brito, não deixa de ser uma das melhores cartilhas, mesmo apresentando alguns senões, pois é baseada em um método racional e lógico de ensino, o qual podia trazer importantes serviços ao ensino da leitura.

Outro artigo a ser destacado é uma carta de autoria de João Köpke em resposta aos artigos de Brito e de Roca Dordal, intitulada Ensino da leitura. O primeiro ponto trabalhado por Köpke refere-se aos desenhos, os quais, para ele, são elementos corriqueiros que devem compor a história, da mesma forma como a Cartilha moderna, de Roca Dordal, faz com suas gravuras tipografadas. Assim, os desenhos são apenas esboços, representações ilustrativas do que está sendo falado, visto que o desenho, para Köpke, nada ensina, apenas auxilia, pois é uma forma de concretização da palavra, sendo ele

\footnotetext{
${ }^{4}$ Neste momento, já há preocupação a respeito de um método para proceder com o ensino coletivo - em contraposição ao ensino individualizado -, havendo uma necessária readequação da divisão do tempo e um rearranjo dos conteúdos. 
secundário ou, até mesmo, desprezível. Posteriormente à representação, propõe que deva ser feita a tradução das ideias expressas pelos desenhos em palavras escritas, momento este caracterizado pelo ensino da leitura. Outro ponto retratado por Köpke, no que tange ao caráter individual, como muitos dos autores retratam seu método, é sobre a eficiência dos métodos. Nessa seara, Köpke diz que se um método é eficiente para uma pessoa, individualmente, é eficiente para a coletividade. O autor ainda acrescenta que por seu método usar de um instrumento de acesso coletivo, o quadro negro, e não usar o livro, que é individual, teria mais mérito no trabalho em grupo. Cláudia Silva (2006, p. 189) destaca que

o eixo de divergência não estava no fato de ser método analítico da palavração inaplicável às classes de ensino coletivo, nem tão pouco na habilidade de desenhar dos professores. O eixo encontrava--se no fato de Roca Dordal e Brito entenderem que as palavras escolhidas para processar 0 método deveriam ser monossílabas e dissílabas, apresentando, assim, um método analítico pela palavração baseando nos procedimentos do método sintético pela silabação, enquanto para Köpke a escolha das palavras deveria considerar a composição das frases e sentenças independentemente do aspecto fonético, ou seja, por meio de um método analítico pela palavração partindo da elaboração coletiva do texto.

Arnaldo Barreto, por sua vez, publicou artigo homônimo Ensino de leitura em tom moderado e conciliador, no qual propõe a tolerância como solução para os problemas relativos aos métodos de ensino:

No meio termo, a nosso ver, é que está a verdade; isto é, se uns concederem iniciar-se o primeiro ensino da leitura pelas sentenças, auxiliando-se esse início com estampas adequadas e sugestivas; e outros admitirem que em cada lição haja um fonema que Ihe seja a base, ou por assim dizer, o seu pivot como o fez Meiklejohn; e que, em subseqüentes lições se decomponham as sentenças em palavras e estas em seus elementos como o exige a natureza da língua materna - para nós, repetimos, o problema naturalmente se resolve. (Barreto, 1902, p. 962)

Com vistas a modernizar a estrutura de ensino no Brasil é que se observam experiências como a Revista de Ensino. Desse modo, percebe-se, neste primeiro momento de publicação da Revista de Ensino, anseio dos professores paulistas pela sistematização do ensino público e a disputa a respeito dos métodos. Em 1902, quando se iniciou a publicação dos artigos estudados, o Brasil começava a colher os primeiros frutos da década de 1890, isto é, das publicações de livros escolares nacionais. Tal relação, entretanto, apenas se solidificou ao longo das primeiras décadas do século 20. Os articuladores do periódico mostram-se muito influenciados por conceitos de educação publicados na Europa e nos Estados Unidos. Contudo, nota-se, também, a preocupação de se criarem materiais nacionais de ensino, com a condição de que fossem alinhados com a perspectiva da Escola Nova. Assim, por meio da leitura dos artigos da Revista de Ensino, verificam-se muitos debates do periódico sobre os dilemas da época e o desejo de se criar uma unidade escolar brasileira.

Pensar no começo do século 20 com recorte temático na alfabetização consiste em debruçar-se na análise dos livros didáticos, pois estes professavam valores que se Hist. Educ. [Online] Porto Alegre v. 17 \begin{tabular}{l|l} 
n. 41 & Set./dez. 2013
\end{tabular} p. $177-194$ 
desejava fossem transmitidos e incorporados ao processo de gradual transformação do povo em cidadãos. A pesquisa de Elomar Tambara ressalta a articulação entre livros didáticos, moral e civismo. Assim, os livros escolares tinham a "função de consolidar atitudes e comportamentos consentâneos com a ordem moral vigente" (Tambara, 2002, p. 50). Nesse sentido, as cartilhas são suportes que concretizam os métodos de alfabetização $0^{5}$. As cartilhas tinham duas características fundamentais, quais sejam, conteúdo e método, dois aspectos que podem ser separados e que, não obstante isso, a todo o momento tornam a confundir-se. Assim, o livro didático pode ser compreendido como ferramenta de preenchimento da lacuna social mediante a formação moral dos cidadãos, uma vez que ele tinha o intuito de transmitir modos moral e socialmente aceitos de falar e de agir à medida que o aluno se apropriava do conhecimento.

\section{Revista de Ensino: segundo momento (1905-1910)}

O segundo momento, 1905-1910, de publicação do periódico paulista é marcado por uma ruptura da Associação Beneficente do Professorado Público do Estado de São Paulo com o governo do Estado. Em virtude disso, a impressão da revista passou a acontecer em uma tipografia privada e, consequentemente, o periódico começou a ser publicado de forma irregular, por falta de verba para publicação. Além dessa mudança, outra modificação percebida por meio da leitura dos artigos é a alteração de foco nos temas publicados. De 1905 até 1908 observa-se que muitos artigos são voltados para questões mais gerais, que debatem o tema da autoridade do professor, do uso de argumentos científicos para amparar ações pedagógicas, da disciplina dos alunos e da instrução pública como ideal. Já a partir de 1909 tornam à pauta da revista artigos voltados para o tema da alfabetização e da leitura, sendo que a maioria dos artigos do segundo momento centra-se na leitura analítica.

Fazendo um recorte temático no que concerne aos temas ligados à alfabetização, um primeiro artigo sobre o tema pode ser destacado. Trata-se do artigo $O$ atual programa de ensino dos grupos escolares e da Escola Modelo, de Augusto Carvalho, no qual o autor debate um tema que vários articulistas da Revista de Ensino trazem à tona: "Em um país novo, que nada, didaticamente, tem de seu, metodologia sempre é uma tese em discussão, até que se firme uma orientação decisiva, emanada das necessidades do meio, ou do fim, que edifica um estabelecimento de instrução" (Carvalho, 1909, p. 3). No começo do século 20 no Brasil, percebe-se o dilema entre adotar métodos estrangeiros ou produzir um método nacional. Assim, os professores da época colocam-se em confronto sobre qual postura tomar diante dessa situação e a Revista de Ensino se apresentou como palco dessas discussões.

A escolha do método analítico para a alfabetização, em oposição ao método sintético, representava a posição dos grupos de professores defensores da escola laica: "Os seguidores do método analítico eram, em sua maioria, republicanos com o discurso voltado para uma democratização do saber escolar e, contrários ao espírito tradicional de

\footnotetext{
${ }^{5}$ Alain Choppin (2004) faz uma importante sistematização no que se refere aos livros didáticos. A divisão é composta de quatro elementos: referencial curricular - tradução do programa escolar; instrumental - prática de métodos e de técnicas de aprendizado; ideológica e cultural - transmitem a língua, a cultura, os valores; documental - espírito crítico dos alunos (texto/imagem). Tal separação auxilia sobremaneira a constituição de um campo de estudos acerca das cartilhas como meio de se apreender o discurso pedagógico referente à alfabetização. 
educação, cujo ensino era calcado em método da igreja" (Bittencourt, 2004, p. 484). No artigo $O$ método analítico: aplicado ao ensino das matérias dos cursos preliminares, de $\mathrm{J}$. C. Jardim, verifica-se um roteiro de ensino, no qual o autor retrata cinco passos para a alfabetização, sendo que o encaminhamento das lições de leitura elementar seria feito pelo método analítico, segundo o plano de Oscar Thompson e baseado na Leitura analítica, trabalho original do professor Theodoro de Moraes.

No que tange o tema da leitura, João Köpke, no artigo Crítica sobre trabalhos escolares, dedica o texto aos "Ilustríssimos Senhores Arnaldo Barreto e Romão Puiggari" (1902, p. 772). O autor apresenta a leitura não como uma habilidade mecânica, mas como um instrumento a ser manejado, porquanto ler é pensar, visto que tal atividade tem componentes, tanto do discurso, quanto da palavra. Köpke escreve que a Cartilha das mães, de Arnaldo Barreto, tem como cordão umbilical a fonética e a palavração, em vez de fazer a leitura por meio da ideia e do pensamento. Já a Cartilha da infância, de Galhardo, modificada por R. Puiggari, tem como base, para Köpke, o método silábico, além de ter lições áridas de leitura. Percebe-se, nesse debate, o impacto que o método analítico proporcionou nos professores brasileiros no começo do século 20.

Outro artigo importante sobre a leitura é de A. Aranha: Discurso. Nele, o autor diz: "A República só será uma realidade quando o analfabetismo tiver desaparecido, quando cada cidadão souber conhecer os seus direitos e os seus deveres" (Aranha, 1907, p. 13). Esse excerto remete ao discurso republicano de civilização do povo, pois que, para o autor, seria por meio do ensino da leitura e da escrita que as pessoas se esclareceriam a respeito dos seus direitos e, consequentemente, defenderiam a República. A educação, nesse sentido, tem um propósito político de aprimorar aquilo que ainda está por vir.

Nesse segundo momento de publicação do periódico paulista, constata-se outro tipo de enfoque, diferente daquele retratado no primeiro momento com os grandes embates das questões pedagógicas. $O$ segundo momento foi muito influenciado pela mudança no processo de publicação da revista, por conta da ruptura com o governo Estado. Isso provocou uma maior articulação entre os professores como categoria, deixando de lado, de certa forma, dilemas sobre métodos e passando a pensar a educação de forma mais ampla, envolvendo os debates acerca da sistematização e implementação de uma escola brasileira.

\section{Considerações finais}

A imprensa periódica pedagógica teve um papel fundamental no começo do século 20 ao projetar mudanças no campo educativo a partir, de um lado, da prescrição das ações escolares por meio da publicação dos seus artigos e, de outro, pelo debate geral das questões educacionais da época. A análise histórica, pela óptica da cultura escolar, permite compreender a gradual constituição histórica das instituições escolares, da formação de professores, das concepções pedagógicas, dos métodos de ensino. Pela leitura dos artigos da Revista de Ensino pode-se observar que neles perpassam concepções pedagógicas e visões de mundo aptas a transmitir parte da dimensão social da época estudada. Naquele momento, os artigos representavam um meio inovador e dinâmico de difusão dos temas abordados, sendo necessário que o leitor desse tipo de material já tivesse previamente algum conhecimento e prática sobre os assuntos educacionais. 
A partir do final do século 19, a leitura e a escrita passaram a ser técnicas ensináveis submetidas ao ensino organizado, sistemático e intencional, que demandavam preparação profissional. Os métodos de alfabetização são princípios teóricos que organizam o trabalho pedagógico do professor em relação aos procedimentos de aquisição das competências da leitura e da escrita. Pensar o tema do método significa refletir sobre o caminho pelo qual a alfabetização se perfaz. Como Berta Braslavsky (1971) aponta, o problema da metodologia aparece concomitantemente com a educação popular, ou seja, com a ampliação do acesso ao ensino. O método passa a ser compreendido como meio facilitador da aquisição da leitura e da escrita: "esse interesse pelo método, que surge e cresce quando se encara a necessidade de ensinar a leitura à grande massa" (lbid., p. 29).

O método, entretanto, não é composto apenas por sua eficácia ou valorização acadêmica, mas pela orientação geral de cada sistema de educação. Trata-se, portanto, de um meio de suporte para o ensino. O método é também uma concepção educacional, pois subjacente aos métodos de ensino sempre há uma perspectiva de educação. Assim, para refletir acerca da história da alfabetização no Brasil, precisa-se de pensar, necessariamente, nos métodos de alfabetização, tendo em vista as acirradas disputas e polarizações em torno destes.

A Revista de Ensino pode ser analisada como um suporte material que movimentou o debate educacional e que colocou em pauta a educação pública da recente nação, fato que trouxe a intensificação de debates acerca dos métodos e das técnicas de ensino, em especial no tocante à busca de instrumentos práticos para se ensinar. Nesse sentido, observa-se, no final do século 19 e no começo do século 20, a busca da sistematização de um método, o qual seria, posteriormente, traduzido em uma cartilha. Isabel Frade (2003) retrata um aspecto importante das questões dos métodos: estes nem sempre estiveram estritamente ligados a uma vertente metodológica ou a uma cartilha. A pesquisadora explica que, sob uma perspectiva histórica, pode-se perceber que, na ausência de livros para alfabetizar, os métodos utilizados pelos professores não tinham ligação explícita com o material utilizado. Quando a vinculação método/livro começou a ser feita, os métodos passam a ter visibilidade por meio dos livros didáticos (Frade, 2003). Por outro lado, essa exacerbada relevância dada ao método e aos livros expressa um íngreme crescimento das instituições de ensino, ou seja, o método pode ser compreendido como um dos elementos que deram centralidade à institucionalização da educação.

Desse modo, no começo do século 20, no Brasil, percebe-se o dilema entre adotar métodos estrangeiros ou produzir um método nacional. Assim, os professores da época colocam-se em confronto sobre que postura tomar diante dessa situação e a Revista de Ensino apresentou-se como grande palco dessas discussões:

Foi, assim, ganhando adeptos o método analítico para o ensino da leitura do todo para as partes -, baseado especialmente em moldes norteamericanos e utilizados na Escola-Modelo anexa à Escola Normal. Inicialmente sem grandes disputas intestinas, os grupos de normalistas que se foram formando em torno dos propagadores da 'nova bússola' passaram, no entanto, a produzir apropriações diferenciadas, gerando-se as disputas em torno do melhor modo de se processar o método analítico para o ensino da leitura. No âmbito dessas disputas, foram-se impondo as 
apropriações de determinados grupos que assessoravam autoridades da administração educacional e cujas propostas ganharam espaço institucional, configurando-se como as primeiras normatizações sobre o ensino da leitura. Essas normatizações, por sua vez, também foram-se impondo, por meio da adoção oficial das cartilhas e da produção de artigos de combate, tradução de textos estrangeiros e relatos de experiências bem-sucedidas, publicados sobretudo na Revista de Ensino. (Mortatti, 2000b, p. 82)

Em resumo, o começo do século 20 foi marcado por intensos debates e pela articulação dos professores em torno da educação. Era o começo do reconhecimento da categoria profissional dos professores, sobretudo com a criação da Associação Beneficente do Professorado Público de São Paulo e da Revista de Ensino, que promoveram espaços para debates sobre a organização da escola pública e, principalmente, sobre os métodos de ensino. Foi nesse período à meia-luz que se expandiu o debate sobre o método intuitivo, o qual visava a ensinar do concreto para 0 abstrato, em contraposição aos métodos de memorização e silabação.

O estudo da cultura escolar não é um domínio da trivialidade e da mera descrição exaustiva, mas uma região impregnada de um modo de vida, de passado e de experiência, de preservação de uma história. Com este trabalho observou-se que a pesquisa histórica não consiste apenas em estudar as mudanças e feitos, mas também em estudar a preservação, com a devida cautela, evidentemente, de não naturalizar ou estagnar os processos históricos.

Compreende-se, assim, que a escola, tal qual conhecemos hoje, é uma construção histórica relativamente recente da história da humanidade e é justamente por esse caráter histórico que se permite refletir e modificar a escola, pois ela não está dada. Vê-se que a escola tem, por excelência, esse duplo sentido: de preservação e de mudança. Preservação porque ela lida a todo o momento com o conhecimento, o qual faz parte do legado cultural da humanidade. Mudança porque se acredita que educar transita no âmbito do incontrolável e do imprevisível.

\section{Referências}

ARANHA, Antonio Alves. Discurso. Revista de Ensino, n. 3, 1907, p. 11-3.

AZANHA, José Mário Pires. Uma idéia de pesquisa educacional. São Paulo: Edusp, 1992.

AZANHA, José Mário Pires. Cultura escolar brasileira um programa de pesquisa. Revista da Universidade de São Paulo, São Paulo, n. 8, 1990/1991, p. 65-69.

BARRETO, Arnaldo. Ensino de leitura. Revista de Ensino, n. 5, 1902, p. 961-966.

BASTOS, Maria Helena. As revistas pedagógicas e a atualização do professor: A Revista do Ensino do Rio Grande do Sul (1952-1992). In: CATANI, Denice; BASTOS, Maria Helena Camara (orgs.). Educação em revista: a imprensa periódica e a história da educação. São Paulo: Escrituras, 2002, p. 47-75.

BITTENCOURT, Circe. Autores e editores de compêndios e livros de leitura (1810-1910). Educação e Pesquisa, São Paulo, v. 30, n. 3, 2004, p. 475-491. Disponível em <http://www.scielo.br/pdf/ep/v30n3/a08v30n3.pdf>. Acesso em: 24 ago. 2006. 
BOTO, Carlota. A civilização escolar como projeto político e pedagógico da modernidade: cultura em classe, por escrito. Cadernos CEDES, Campinas, v. 23, n. 61, 2003, p. 378397. Disponível em <http://www.scielo.br/pdf/ccedes/v23n61/ a08v2361.pdf>. Acesso em: 24 ago. 2006.

BOTO, Carlota. Ler, escrever e se comportar. a escola primária como rito do século XIX português (1820-1910). São Paulo: USP, 1997. 650f. Tese (doutorado em História Social). Faculdade de Filosofia Letras e Ciências Humanas, Universidade de São Paulo.

BRASLAVSKY, Berta. Problemas e métodos no ensino da leitura. São Paulo: Melhoramentos, 1971.

BRITO, Joaquim Luiz. Cartilha moderna. Revista de Ensino, n. 2, 1902, p. 322-325.

CARVALHO, Augusto. $O$ atual programa de ensino dos grupos escolares e da escola modelo. Revista de Ensino, n. 2, 1909, p. 3-8.

CARVALHO, Marta. A escola e a República. São Paulo: Brasiliense, 1989.

CATANI, Denice. Educadores à meia-luz: um estudo sobre a Revista de Ensino da Associação Beneficente do Professorado Público de São Paulo 1902-1918. São Paulo: USP, 1989. 392f. Tese (doutorado em Educação). Faculdade de Educação, Universidade de São Paulo.

CATANI, Denice; SOUSA, Cynthia Pereira de. Imprensa periódica educacional paulista (1890-1996). São Paulo: Plêiade, 1999.

CASPARD, Pierre; CASPARD, Pénélope. A imprensa pedagógica e formação contínua dos professores (1815-1939). In: CATANI, Denice; BASTOS, Maria Helena (orgs.). Educação em Revista: a imprensa periódica e a história da educação. São Paulo: Escrituras, 2002, p. 33-46.

CHOPPIN, Alain. História dos livros e das edições didáticas: sobre o estado da arte. In: Educação e Pesquisa, São Paulo, v. 30, n. 3, 2004, p. 549-566. Disponível em: $<$ ttp://www.scielo.br/pdf/ep/v30n3/a12v30n3.pdf>. Acesso em: 24 ago. 2006.

D’ÁVILA, Antonio. Poliantéia Comemorativa - 1846-1946 do 1ํ. Centenário do Ensino Normal Superior de São Paulo. São Paulo: Gráfica Brescia, 1946, p. 77-114.

EDITORIAL. Revista de Ensino, 1902, n. 1, abril, p. 3-5.

FERNANDES, Rogério. Os caminhos do ABC. Porto: Porto Editora, 1994.

FRADE, Isabel. Alfabetização hoje: onde estão os métodos? Presença pedagógica, Belo Horizonte, v. 9, n. 50, 2003, p. 17-29. Disponível em: <http://fundelta.com.br/webroot/doc/ 40db1aaacb.pdf>. Acesso em: 24 ago., 2011.

GINZBURG, Carlo. Sinais: raízes de um paradigma indiciário. In: GINZBURG, Carlo. Mitos, emblemas, sinais: morfologia e história. São Paulo: Companhia das Letras, 1990, p. 143-179.

GOODY, Jack; WATT, lan. Cultura letrada: algumas considerações finais. In: GOODY, Jack; WATT, lan. As conseqüências do letramento. São Paulo: Paulistana, 2006, p. 57-74.

JARDIM, J. C. O método analítico: aplicado ao ensino das matérias dos cursos preliminares. Revista de Ensino, n. 2, 1907, p. 35-39.

JULIA, Dominique. A cultura escolar como objeto histórico. Revista Brasileira de História da Educação, Rio de Janeiro, n. 1, 2001, p. 9-44, Disponível em: <http://www.sbhe.org.br/ novo/rbhe/RBHE1.pdf>. Acesso em: 24 ago., 2006. 
KÖPKE, João. Ensino da leitura. Revista de Ensino, 1902, n. 4, outubro, p. 772-793.

MORTATTI, Maria. Cartilha de alfabetização e cultura escolar: um pacto secular. Cadernos Cedes, Campinas, n. 52, 2000a, p. 41-54. Disponível em: <http://www.scielo.br/ pdf/ccedes/v20n52/a04v2052>. Acesso em: 24 ago., 2011.

MORTATTI, Maria. Os sentidos da alfabetização. São Paulo: Unesp, $2000 \mathrm{~b}$.

NAGLE, Jorge (org.). Educação e linguagem. São Paulo: Edart, 1976.

NÓVOA, António. A imprensa de educação e ensino: repertório analítico séculos 19 e 20. Lisboa: Instituto de Inovação Educacional, 1993.

PESSANHA, Eurize Caldas; DANIEL, Maria Emília Borges; MANEGAZZO, Maria Adélia. Da história das disciplinas escolares à história da cultura escolar: uma trajetória de pesquisa. Revista Brasileira de Educação, Rio de Janeiro, n. 27, p. 57-69, 2004. Disponível em: <http://www.scielo.br/pdf/rbedu/n27/n27a04.pdf.> Acesso em: 24 ago., 2011.

RAMOS, Graciliano. Infância. Rio de Janeiro/São Paulo: Record, 1993.

REVISTA DE ENSINO. São Paulo, v. 1, n. 1-5, 1902.

REVISTA DE ENSINO. São Paulo, v. 2, n. 1-6, 1903-1904.

REVISTA DE ENSINO. São Paulo, v. 2, n. 6, v. 3, n. 1-5, 1904.

REVISTA DE ENSINO. São Paulo, v. 3, n. 6, v. 4, n. 1-4, v. 5, n. 1-2, 1905-6.

REVISTA DE ENSINO. São Paulo, v. 3, n. 6, v. 4, n. 1-6, v. 5, n. 1-2, v. 6, n. 3-5, 19051907.

REVISTA DE ENSINO. São Paulo, v. 11, n. 1-4, 1912-1913.

REVISTA DE ENSINO. São Paulo, n. 1, 1912-1914.

REVISTA DE ENSINO. São Paulo, v. 15-8, 1916-1918.

REVISTA DE ENSINO. São Paulo, n. 1-4, 1918.

ROCA DORDAL, Roman. Cartilha moderna. Revista de Ensino, 1902, n. 2, junho, p. 213225.

SILVA, Claudia Panizzolo. João Köpke e a escola republicana: criador de leituras, escritor da modernidade. São Paulo: PUCSP, 2006. 358f. Tese (doutorado em educação). Faculdade de Educação, Pontifícia Universidade Católica de São Paulo.

SILVA, llíada. A Associação Beneficente do Professorado Público do estado de São Paulo e a construção de uma identidade sócio profissional docente 1901-1910. São Paulo, USP, 2004. 316f. Tese (doutorado em Educação). Faculdade de Educação, Universidade de São Paulo.

SOUZA, Rosa Fátima de. Templos de civilização: um estudo sobre a implementação de Grupos Escolares no estado de São Paulo (1890-1910). São Paulo: USP, 1997. $284 f$. Tese (doutorado em Educação). Faculdade de Educação, Universidade de São Paulo.

STEPHANOU, Maria; BASTOS, Maria Helena. (orgs.). Histórias e memórias da educação no Brasil. Petrópolis: Vozes, 2005.

TAMBARA, Elomar. Trajetórias e natureza do livro didático nas escolas de ensino primário no século 19 no Brasil. Hist. Educ., Pelotas: UFPel, 2002, p. 25-51. 
LOUISA CAM PBELL MATHIESON é estudante do curso de doutorado em Educação na Universidade de São Paulo, onde também concluiu mestrado (2012) e se graduou em Pedagogia (2009).

Endereço: Rua Comendador Elias Zarzur, 2266 - 04736-003 - São Paulo - SP Brasil.

E-mail: louisa.mathieson@usp.br.

Recebido em 16 de julho de 2011.

Aceito em 14 de dezembro de 2012. 